\title{
Understanding the layout of early coastal settlement at Unguja Ukuu, Zanzibar
}

\section{Tom Fitton \& Stephanie Wynne-Jones*}

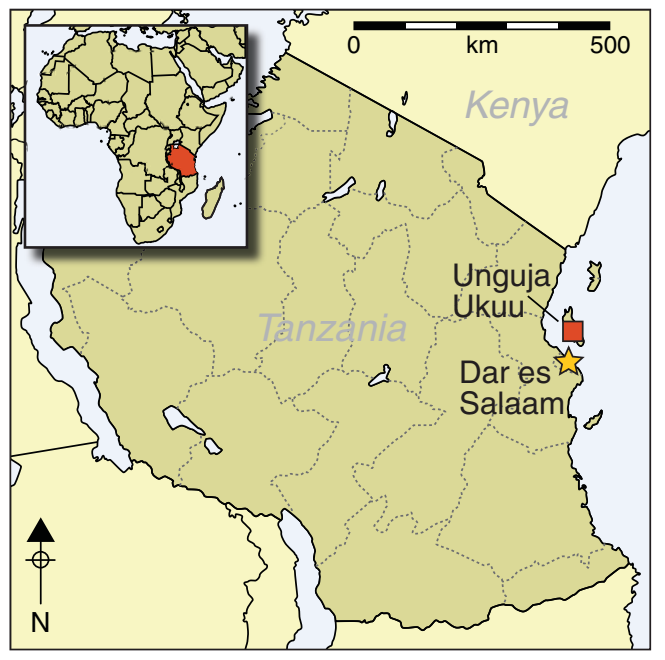

Keywords: Tanzania, Swahili, magnetometry, geophysical survey
New investigations at the coastal settlement of Unguja Ukuu in Zanzibar have demonstrated the effectiveness of magnetometry as a survey method. The early occupation of this Swahili port, from the sixth century $A D$, presents a unique opportunity to develop our understanding of the growth and development in settlement and trade along the East African coast. The geophysical survey has allowed the size of this important site to be reassessed and an industrial component to be identified. It also offers an insight into the role that early Islamicisation may have played in helping to establish the settlement as a key port during the growth of the Indian Ocean trade network.

\section{Introduction}

The site of Unguja Ukuu occupies the Makime Peninsula, a sandy spit at the south-western end of the island of Unguja (Figure 1), which is part of the Zanzibar archipelago along with the islands of Tumbatu and Pemba. It has long been recognised as an important trading site dating to the earliest period of coastal settlement in this region and has been subject to successive archaeological projects aimed at exploring its chronology and contacts. Unguja Ukuu, along with many sites of this kind along the eastern coast of Africa, was first settled in the sixth to seventh centuries $\mathrm{AD}$, and was connected with networks of Indian Ocean trade from the start. These networks are visible in the archaeology via the record of imported goods and exotic foodstuffs that have been found from the earliest levels.

Previous research at Unguja Ukuu has sought to understand the chronology of the settlement and to map connections with particular trading partners over many centuries.

* Department of Archaeology, University of York, King's Manor, York YO1 7EP, UK (Email: stephanie.wynnejones@york.ac.uk) 


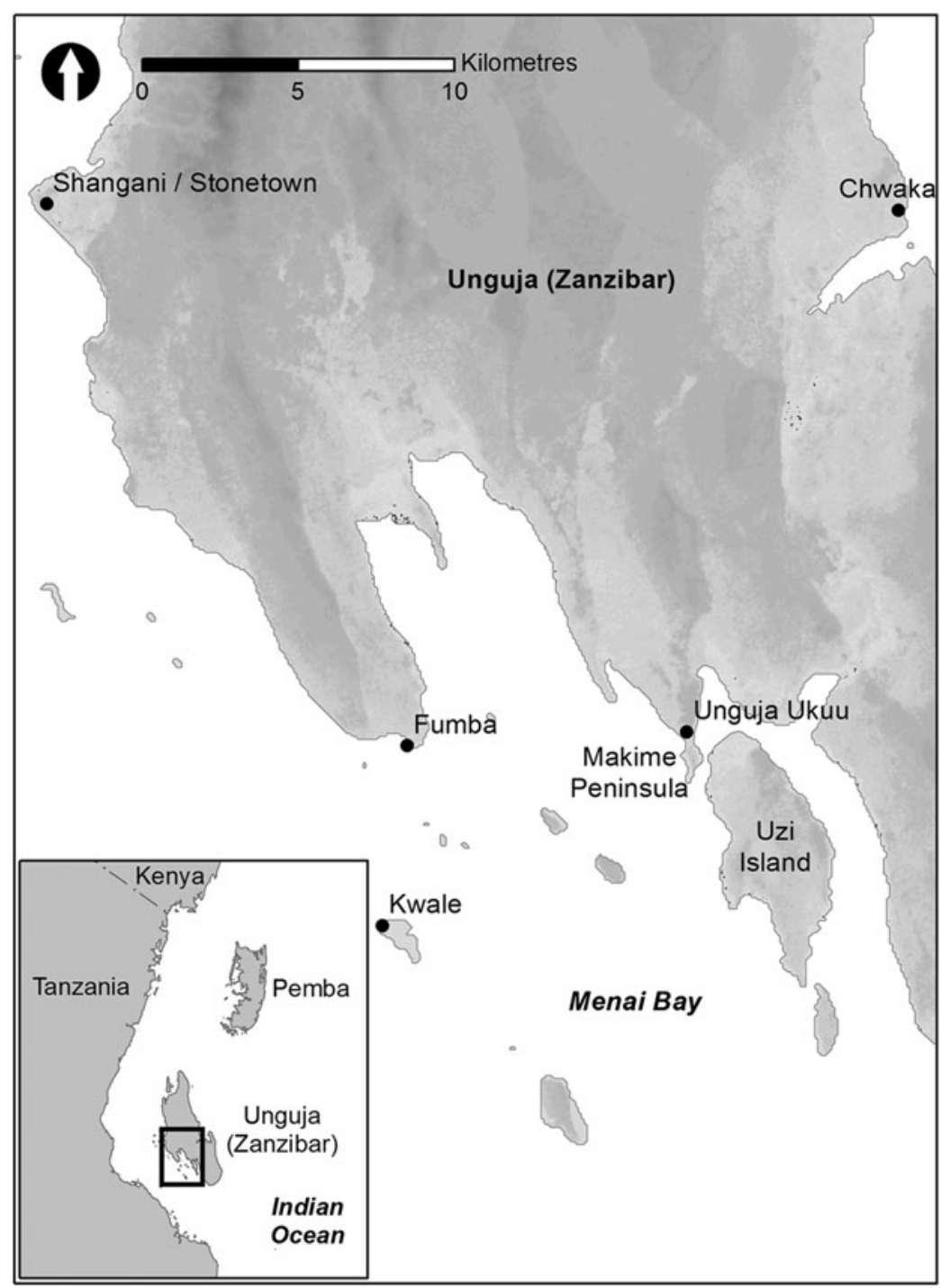

Figure 1. Map of the Zanzibar archipelago, showing the islands of Unguja and Pemba, and the location of Unguja Ukuu.

Our project, by contrast, was aimed at understanding the nature of Unguja Ukuu as a settlement. A programme of geophysical survey and limited test excavations together contribute a picture of the general layout of the site and provide a framework in which to understand previous test excavations at the site (Horton \& Clark 1985; Juma 2004). In particular, this survey was focused towards understanding the interface between the site and the ocean. The results point to the existence of a larger settlement than previously imagined, with a busy waterfront, and bordering a shallow harbour where vessels would probably have been beached. Most notably, they revealed the existence of a probable early mosque immediately adjacent to the waterfront. 


\section{Unguja Ukuu}

Although evidence for occupation at cave sites on both Unguja and Pemba dates back many thousands of years (Chami 2001, 2009; Sinclair et al. 2006), it is only from the seventh century AD that a record of consistent settlement can be traced in the Zanzibar archipelago. Sites characterised by 'Tana Tradition' ceramics are found along the coast of both Zanzibar and Pemba (Horton \& Clark 1985; LaViolette \& Fleisher 1995). From their earliest iterations, these sites were connected to long-distance maritime trade, with imports including ceramics from the Persian Gulf and India, glass and glass beads. They were also significant manufacturing centres of iron and of shell beads. Inhabitants had a mixed diet that involved some hunting, a heavy emphasis on fish consumption, as well as the keeping of chicken; pearl millet and sorghum were the staple crops (Walshaw 2010, 2015). Architecture in the earliest settlements was entirely of daub and timber. Many sites were substantial even at this early date, covering between 4 and 25ha, and have been described as large villages (Fleisher \& LaViolette 2013).

At around $\mathrm{AD} 900$, older sites such as Unguja Ukuu were either abandoned or greatly reduced in size, and a new settlement pattern emerged, favouring remote islands or peninsulas (Horton in press). Some of these settlements may have had their origins in the ninth century $\mathrm{AD}$, but from the eleventh century, they took on urban forms based around coral buildings. The period between $\mathrm{AD} 1100$ and 1400 was particularly prosperous on the islands of Zanzibar.

Archaeology in the archipelago has revealed a great deal about this history of settlement, including its chronology and links with overseas partners. The sites of Unguja Ukuu (Horton \& Clark 1985; Juma 2004), Mkokotoni (Horton \& Clark 1985) and Tumbatu (Horton \& Clark 1985; Horton in press) have all been the subject of detailed archaeological excavations. Elsewhere in the archipelago, excavations have been supplemented by systematic settlement survey that has helped relate sites to a broader landscape (Fleisher 2003, 2010). Nonetheless, we still only partially understand the full layout of these settlements, how they related to the sea and to maritime resources, and how the excavated portions fitted within the overall layout.

Previous test-pit excavations at Unguja Ukuu (Horton \& Clark 1985; Juma 2004) have established the presence of settlement remains stretching more than $300 \mathrm{~m}$ inland into the peninsula, and deep archaeological sediments extending to within around $20 \mathrm{~m}$ of the foreshore (Figure 2). These have to some extent been mapped using resistivity survey and coring (Juma 2004), although the results were somewhat inconclusive and thus were used chiefly as a guide to the depth of deposits rather than as a means of understanding site layout. The emergent picture is of a site with rich archaeological deposits indicating occupation from at least the seventh, if not sixth, century AD (Juma 1996). It was involved with Indian Ocean trade from the start, as evidenced by the record of imported beads, glass and ceramics, as well as the presence of exotic plants (Boivin et al. 2014: 558). The more mundane artefacts such as ceramics, and the huge majority of the plant and food remains, position Unguja Ukuu among its contemporaries in the region, with a mixed economy of agriculture, fishing and hunting, and a variety of craft activities.

(C) Antiquity Publications Ltd, 2017 


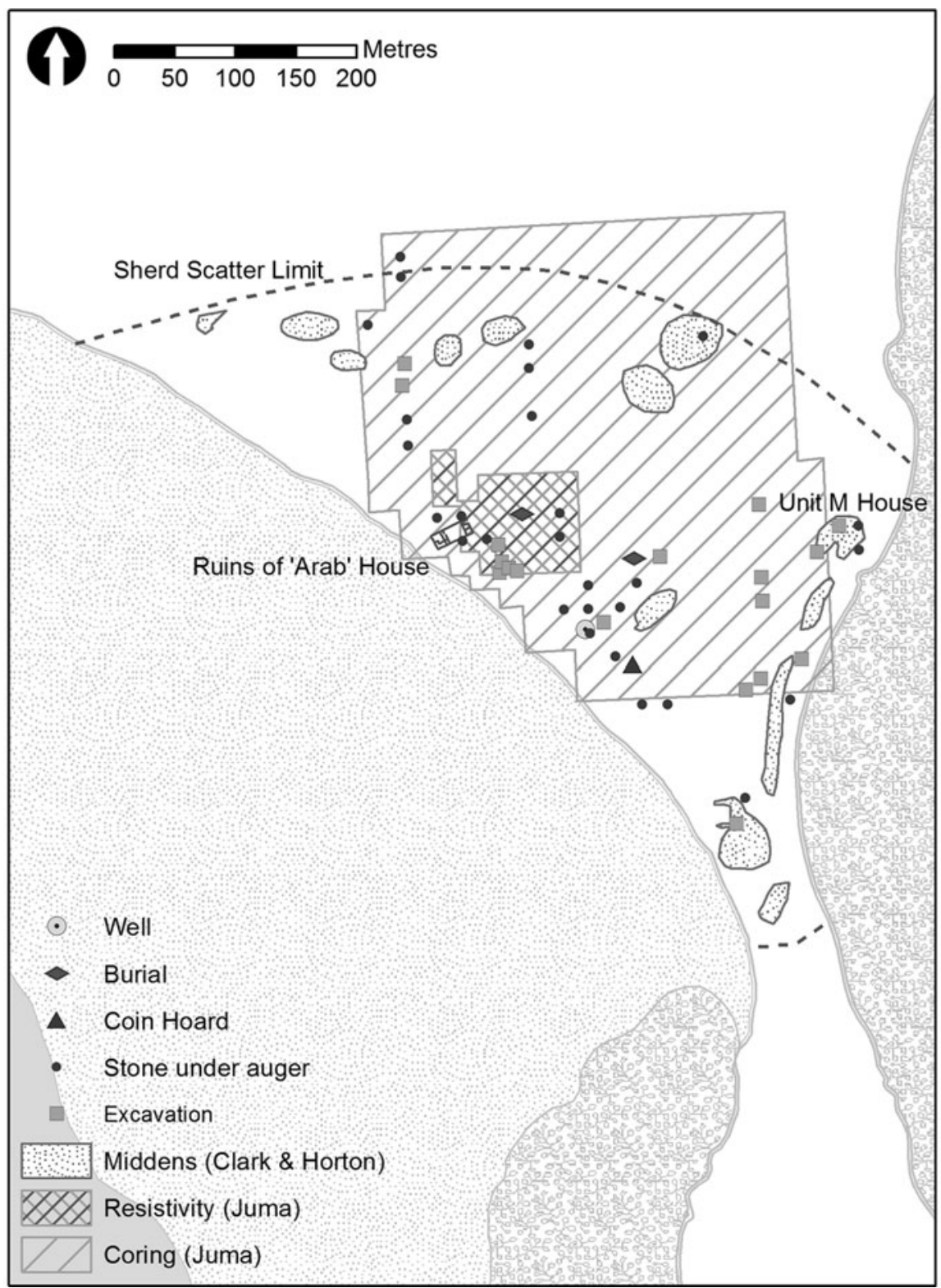

Figure 2. Map of previous excavations and interpretations of the archaeology at Unguja Ukuu.

Excavations at Unguja Ukuu have not, however, explored the layout in the kind of detail that would allow us to consider the settlement's interface with the ocean, or the ways that it was structured around marine and terrestrial resources. No attempt has previously been made to identify a harbour area, or establish whether the site was maritime-oriented (Fleisher et al. 2015). Juma (2004) identified coral-rag architecture and a mosque in the inland urban zone of Unguja Ukuu, and Horton and Clark (1985) reported a possible 
mosque overlooking the creek to the east. Local reports suggest that a fifteenth-century 'Arab' house and a mosque once stood close to the beach of Menai Bay to the west (Horton \& Clark 1985), but coastal erosion has damaged the house, and recent construction has buried or destroyed the remains of the mosque (Figure 2). It has been assumed that the creek was the principal focus of settlement and harbour activity in the later phases of the site, but the earlier and richer phases remain obscure, understood only through small test excavations.

\section{Methodology}

The research reported here was intended to explore the broader layout of Unguja Ukuu, in order to provide a context for the knowledge gained through previous test excavations. In particular, we were interested in the way that the site was structured around the demands of ocean-going trade. Research conducted under the auspice of the Entrepôt Project at the University of York (in collaboration with Aarhus University, Denmark) has sought to explore the layout of several early ports of trade in northern Europe, the Mediterranean region, East Africa and India during this period for comparative purposes.

Fieldwork was based on magnetic gradiometry, which has proved successful at defining site extent and at locating archaeological features elsewhere on the Swahili coast (Fleisher et al. 2012; Wynne-Jones 2012; Welham et al. 2014). Magnetometry survey has the potential to recover areas of activity, to pick up on disturbed soils and to pinpoint industrial activity. As survey at Unguja Ukuu had a particular interest in how the site was positioned in relation to port facilities and the ocean, and how that relationship might have changed over time, the area between the town and the ocean was explored, with a view to locating harbour facilities and identifying anchorages. Magnetic gradiometry is based on the systematic, passive detection of ground magnetic field orientation across a survey area. Anomalous differences in magnetic field strength and orientation may be measured as a result of the induced polarisation of ferrous objects such as metals or fired ceramics; by the thermoremanent polarisation of iron oxides in the soil as a result of heating beyond the Curie point; the magnetic enhancement of soils as a result of disturbance and redeposition; and even because of the presence of objects with an unusually low magnetic signature relative to their surrounding environment, such as coral. The technique thus has a wide variety of applications, and in this instance it allowed the extent of the site to be mapped using trace signatures of sub-surface features and key activity areas.

Without ground-truthing it can be difficult to determine the cause of magnetic anomalies, as the range and amplitude of such anomalies across a given site are in part related to the quantity of iron oxides in the soil. The shape, amplitude and clustering of anomalies may provide some indication of activity; bipolar anomalies, for example, indicate induced magnetism, but might be the result of either ferrous materials or magnetic thermoremanence. In the case of Unguja Ukuu, we hypothesised that industrial activity such as hearths, kilns and smelting or iron-working might be identifiable by the clustering of induced magnetic anomalies. At the same time, the probable zone of settlement was surveyed in the hope of reconstructing building plans of wattle-and-daub architecture (C) Antiquity Publications Ltd, 2017 


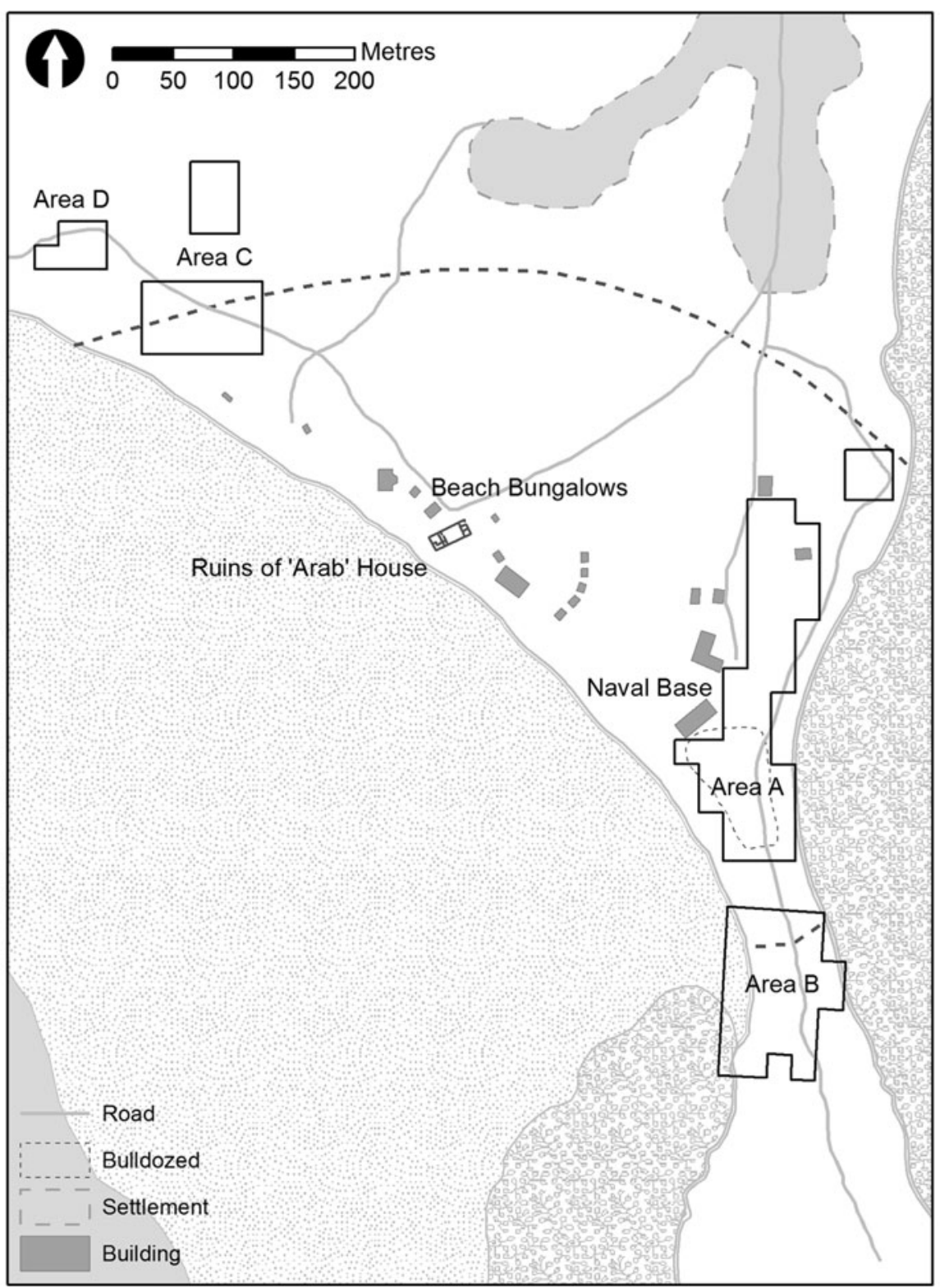

Figure 3. Map showing the areas (A-D) selected for survey. Current structures, roads, standing archaeological ruins and bulldozed areas are also shown.

through either the magnetic enhancement of structural foundations and postholes, or the thermoremanence of burnt daub structures, as at Songo Mnara (Welham et al. 2014).

Four areas of the site were selected for survey (Figure 3). Three were covered during a season of fieldwork in October 2013. Survey of the fourth area was completed during another season in January 2014, and the results for other areas were refined with the use of a metal detector to search for modern debris. Limited test excavations were undertaken 


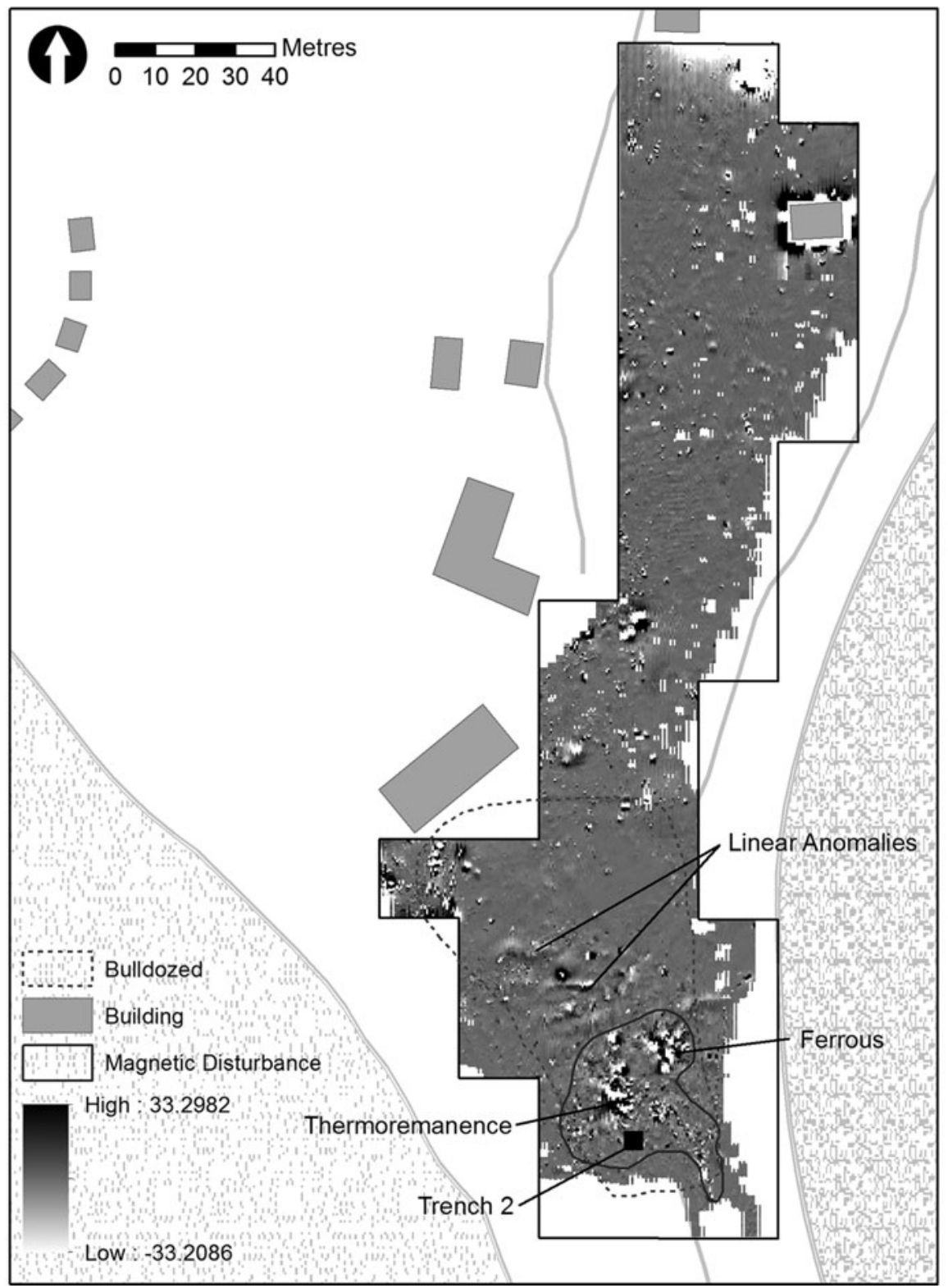

Figure 4. Magnetometry results from the survey of area A, showing the location of anomalies, ferrous materials, thermoremanence and the placement of trench 2.

in 2014 to ground-truth the anomalies seen via the magnetometry (shown as trench 2, Figure 4, and trench 1, Figure 5).

A $20 \times 20 \mathrm{~m}$ grid was staked out across each area using a Leica Zeno DGPS to locate key grid points, and $2 \mathrm{~m}$ transect markers were then laid east-west across the edges of those grids using $30 \mathrm{~m}$ measuring tapes. The grids aided precision in data collection, and allowed us to locate the geophysical data results accurately in the GIS. The survey was conducted using a (C) Antiquity Publications Ltd, 2017 


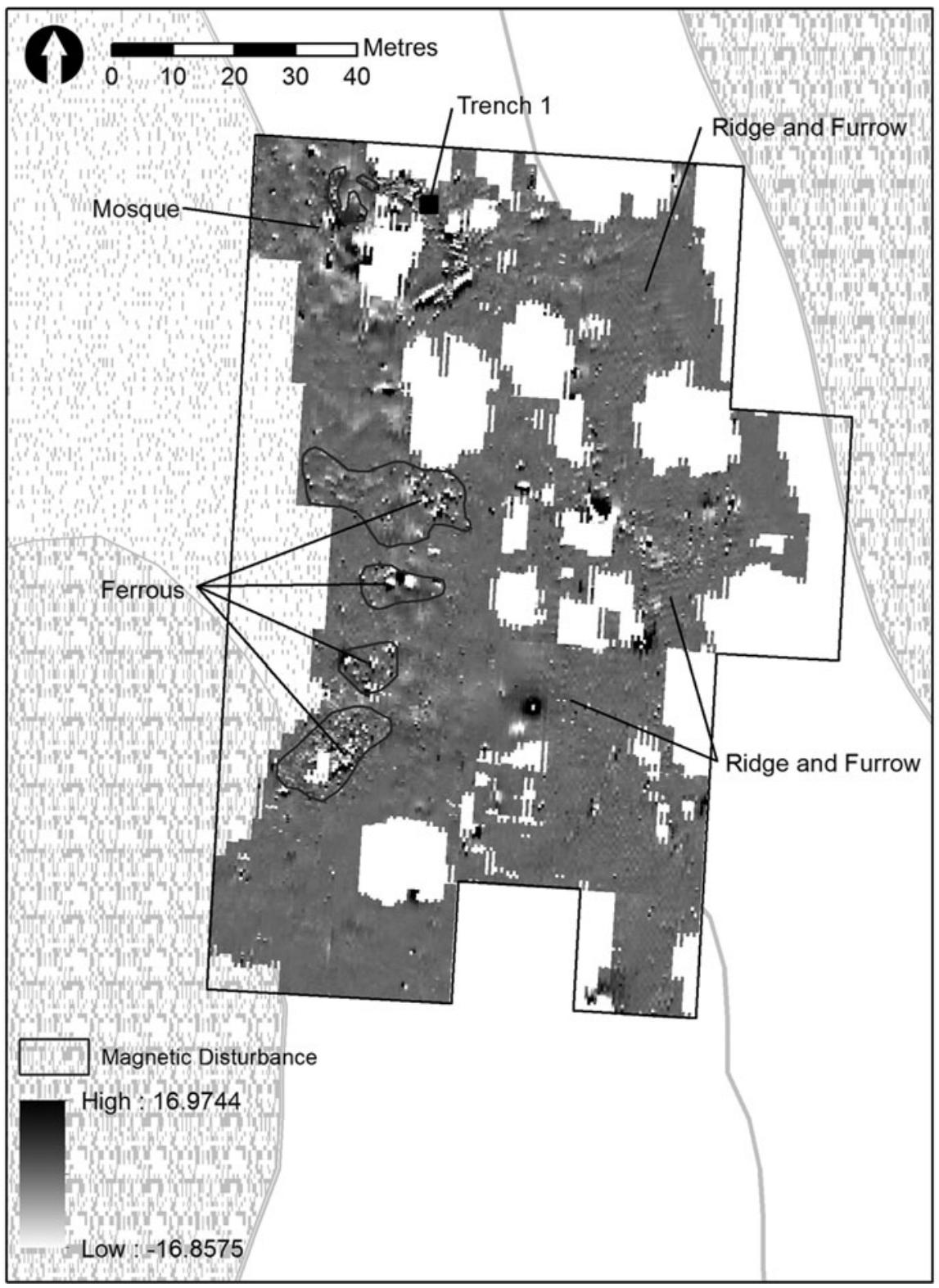

Figure 5. Magnetometry results from the survey of area B, showing the location of the mosque, ferrous materials, traces of ridge-and-furrow farming and the placement of trench 1.

Bartington Grad-601 dual sensor magnetic field gradiometer, and readings were taken at a resolution of $0.125 \times 0.5 \mathrm{~m}$. This strategy enabled us to gather high-resolution data in spite of the frequent obstacles presented by trees, high grass and thorn bushes. In order to avoid sensor drift in the high temperatures, the system was readjusted on a recorded reference point at least once every hour. Surface features were planned using the Leica DGPS where 
they might assist with interpreting the results of the survey, or the georectification of images; these were added to the GIS during post-processing.

Data from the magnetometer was downloaded using the native Bartington Grad-601 download utility, and imported into ArchaeoFusion, a beta-test program published by CAST (Centre for Advanced Spatial Technologies) for processing. Post-processing of the data was kept to a minimum, and consisted of Zero Mean Traverse, clipping to 3 standard deviations of the mean, and destaggering. Raw and interpolated images were georectified and imported into ArcGIS using DGPS data collected in the field. Magnetic anomalies were traced and numbered, and those that could be attributed to modern features that had been mapped during the survey were filtered. The remaining anomalies were then analysed according to shape, size and form. Distinct anomalies were re-examined in ArchaeoFusion using the raw data to isolate signature patterns of field strength and amplitude in order to identify ferrous metals or thermoremanence. This procedure enabled the predictive modelling of the cause and nature of anomalies and clusters of features. These assessments are outlined and discussed below.

\section{Results}

\section{Area A}

The strip of land surveyed in area A stretches north-south from an elevated ridgeline within the assumed zone of settlement, onto a low-lying land 'bridge' linking to the peninsula (Figure 4). A naval base has been built over the area in recent years, and a road and parade ground have been cleared by bulldozer, creating a section revealing loam sediments $1-2 \mathrm{~m}$ thick overlying archaeological materials and degraded daub. The walls of several coral-rag buildings have also been exposed or destroyed by the creation of this road. The depth of overburden masks the magnetic signature of buried archaeological materials in much of this zone, but in the areas cleared by bulldozers, we identified a number of particularly distinct anomalies. Ceramics of the Early Tana Tradition (Fleisher \& Wynne-Jones 2011) and imported Turquoise-Glazed ceramics recovered from the surface and from the bulldozed regions of area A indicate occupation spanning the seventh to tenth centuries $\mathrm{AD}$.

Sweeping the area with a metal detector allowed us to exclude significant contamination from modern debris. It also identified a small number of metal archaeological artefacts close to the surface, including fragments of lead fishing weights, copper wire, a copper-alloy tubular container and a possible flask cap.

Around the parade ground we recorded a series of intense bipolar, amorphous magnetic anomalies in an area of general magnetic disturbance, and a small number of weaker linear anomalies (Figure 4). These anomalies are in the vicinity of the previously estimated southern edge of the settlement, an area that Horton and Clark have described as a midden, where their test-pit UU1 revealed large quantities of iron slag and possible haematite ore (Horton \& Clark 1985; Horton in press). The broad region of magnetic disturbance indicates a collection or spread of ferrous material, and through its remarkable similarity in shape to those mapped in 1984, it seems likely to represent the middens recorded by Clark and Horton. The larger bipolar anomalies may represent either large ferrous artefacts

(C) Antiquity Publications Ltd, 2017 
such as metal objects or an overlapping group of thermoremanent areas. A test pit $0.5 \times$ $0.5 \mathrm{~m}$ (Figure 4, trench 2) was excavated on the edge of one of these bipolar anomalies, demonstrating that at least $0.9 \mathrm{~m}$ of archaeological deposits still survive beneath the surface. Two distinct phases of activity were recognisable even within the limits of this small area. The upper, later phase probably corresponds to the midden deposits previously excavated by Clark and Horton, and was characterised by clay deposits, possible daub remains, local ceramics and ash. Beneath this was an almost barren context, separating the upper midden deposits from a dense shell midden. Time constraints and the restricted size of the test-pit prevented excavation to the base of this shell midden, but its presence indicates an earlier use of the site.

Despite concerns that this part of Unguja Ukuu had been entirely destroyed by the bulldozing, it now seems probable, even with the extensive damage, that an unknown quantity of stratified remains is still preserved. The broad area of induced magnetic material highlighted in the gradiometry results may represent remains exposed and spread by bulldozing, but the similarity in shape of the 2013 anomaly and the middens mapped in 1984 suggests that the archaeological contexts are surprisingly intact. The large overlapping bipolar anomalies indicate the possibility of in situ thermoremanent material. The linear anomalies are difficult to explain without excavation, as the parallel positive and negative magnetic signatures could represent either archaeological structural remains or the more prosaic banking of earth in front of a bulldozer.

North of this region, the ground has not been modified by recent earthworks, and a bank at the edge of the clearance rises to sloping ground. On this higher ground, the only clearly identifiable anomalies relate to modern features such as coral pieces lining the road, waste metal, recent burning activity in rubbish pits, and agricultural ridge and furrow, presumably pre-dating the construction of the naval base, and possibly related to the nineteenth-century occupation of the site described by Juma (2004). The stratigraphy revealed by the cutting of the road leads us to believe that this lack of magnetic anomalies is not due to an absence of archaeological activity but to the masking effect of deep overlying soil deposits.

\section{Area B}

Area $B$ is presumed to be the location of the main settlement; it is located to the south of area $\mathrm{A}$, at the narrowest point of the Makime Peninsula, and is perhaps the most exciting area surveyed (Figure 5). From the narrow 'neck', the peninsula rises in a steep ridgeline to the south for about a kilometre, while widening to the east and west. On the eastern side of the ridge, the extensive remains of modern ploughing are still visible running down the steep slope to the mangroves, and these show up clearly as linear disturbances in the results (Figure 5). Erosion or quarrying on the western side of the ridge has created a trough at the base of the slope, which appears to act as an occasional tidal pool behind the beach on the seaward side. The results of the magnetic gradiometry indicate an area of mixed magnetic material across the upper part of this beach, a short distance from where undiagnostic local ceramics are being exposed by tidal erosion. The magnetic anomaly is probably the result of mixed ferrous materials, but does not correlate with debris on the surface, and it is not clear whether it represents modern or archaeological waste. Survey of the foreshore was 


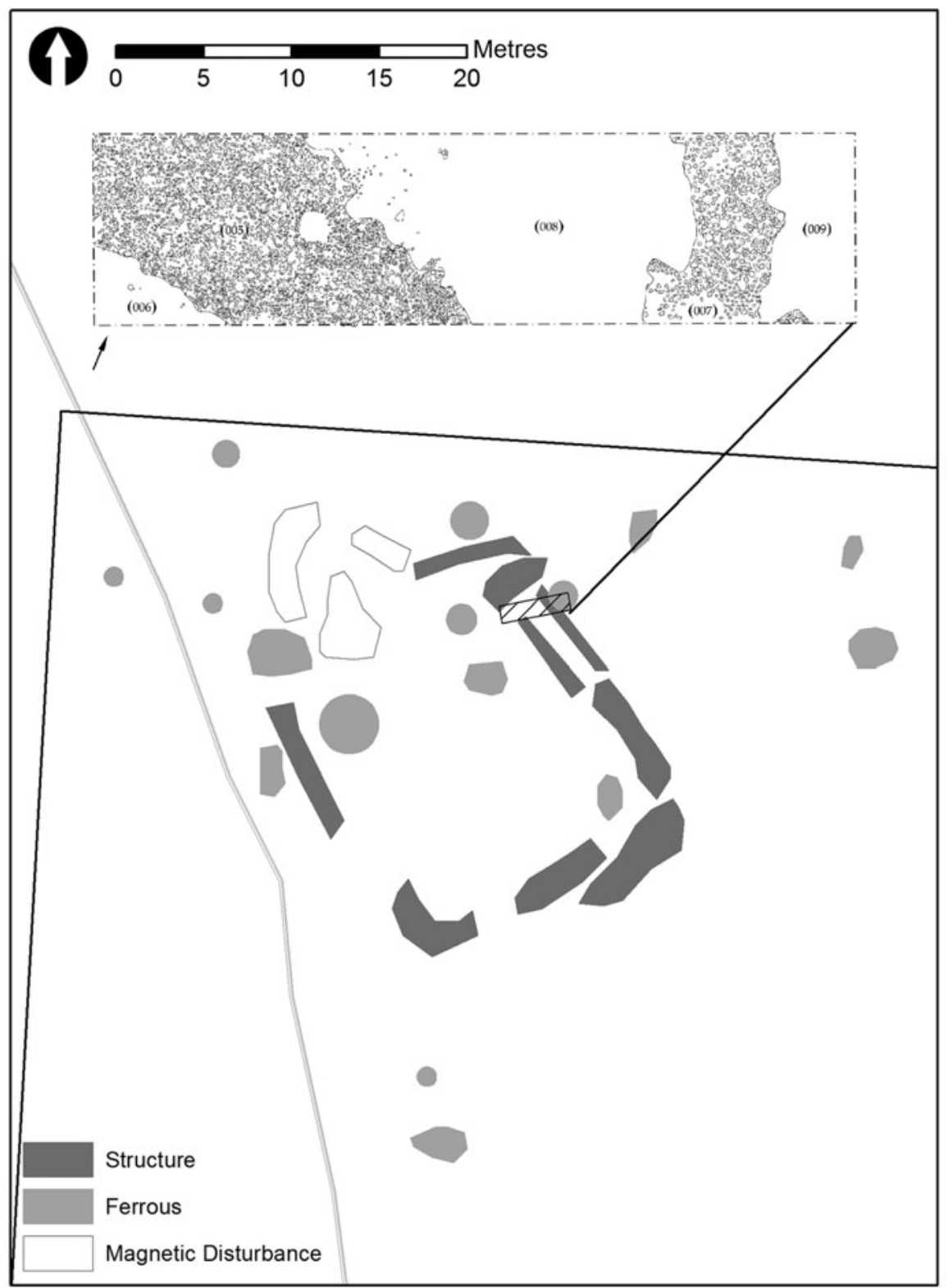

Figure 6. Excavation plan of the trench spanning the eastern wall of the mosque. Contexts (005) and (007) are lines of coral debris.

hampered by incoming tides, but faint anomalies indicate that further work in this region may be useful, if only to establish the archaeological, modern or geological origins of these features.

The most interesting feature lies under the break of slope at the top of the beach, at the northern edge of area B. Here we have identified a distinct rectangular structure, approximately $18 \times 13 \mathrm{~m}$ on an alignment of $328^{\circ}$ (Figure 6). This may represent the (C) Antiquity Publications Ltd, 2017 
remains of a mosque, as the orientation of the structure falls within an acceptable degree of error for the relevant period (Horton 1991), and matches the alignment of the unit M house discovered by Juma (2004), which Horton has again suggested may represent a new style of mosque (Horton in press). The anomaly reported here is to the south of area A, and outside the limits of the settlement estimated by Clark and Horton based on middens identified and partially excavated in 1984 (Horton \& Clark 1985).

The anomaly is located just above the beach. The faintness of traces on its western side appear to indicate erosion along the side facing the beach, but a parallel linear feature on the eastern side was interpreted as a double wall or an aisle. In order to test this, we laid out a $1 \times 4 \mathrm{~m}$ trench (Figure 5, trench 1 ) running east-west across the eastern wall of the anomaly from the interior (Figure 6). Excavation revealed that the double linear magnetic anomaly was caused by two lines of Porites (finger coral) fragments whose orientationas indicated by the magnetometry-was roughly $330^{\circ}$. The Porites fragments are not as large as the building blocks reported by Juma (2004), falling between 20 and $100 \mathrm{~mm}$ in diameter, but may represent the remains of a wall of larger, robbed-out blocks, a hypothesis supported by the excavated sections. There were few finds associated with these contexts, and no diagnostic potsherds, but fragments of glass from the coral contexts may be similar to finds from Juma's period Ib, between AD 750 and 900.

Excavation also recovered evidence of wattle-and-daub architecture below, and immediately adjacent to, the coral debris. The interface between the two was unclear, but it seems that a roughly contemporaneous wattle-and-daub house, associated with a dense concentration of artefacts, used to exist next to the robbed-out coral structure. At the lowest levels, postholes and a sandy floor delineated the interior area of this structure. Diagnostic Early Tana Tradition ceramics date it to the seventh to tenth centuries AD.

\section{Area $C$}

Area $\mathrm{C}$, to the west of the main site, covers a ridge behind the beach of Menai Bay and a small area of low-lying land beyond (Figure 7). This area is currently devoted to cultivation, and pedestrian survey returned a large number of semi-fired daub fragments, along with ceramics that appear to belong to the eleventh to thirteenth and nineteenth centuries. We also recovered a single coin from the ridgeline, with an illegible inscription but similar in size and shape to East African coins minted at sites such as Kilwa Kisiwani or Tumbatu during the early second millennium AD (Wynne-Jones \& Fleisher 2012).

Gradiometry results from area $\mathrm{C}$ revealed a cluster of bipolar and linear magnetic anomalies on the southern, beach-facing side of the ridge, which might be the remains of burnt daub structures or industrial activity. The signatures are not as intense as those found in area $\mathrm{A}$, and the anomalies do not extend inland, despite the partially fired daub fragments recovered in that area. Some of the anomalies seem to relate to ancient activity, and generally gave no result with the metal detector; shallow excavations to investigate the few that did revealed a series of thick iron posts and degraded concrete buried upright in the ground. Several early twentieth-century coins were also found in the area, including four British shillings, one of which was identifiable as a 1930s George V issue. It seems that a structure or shelter was erected here in the early to mid twentieth century. 


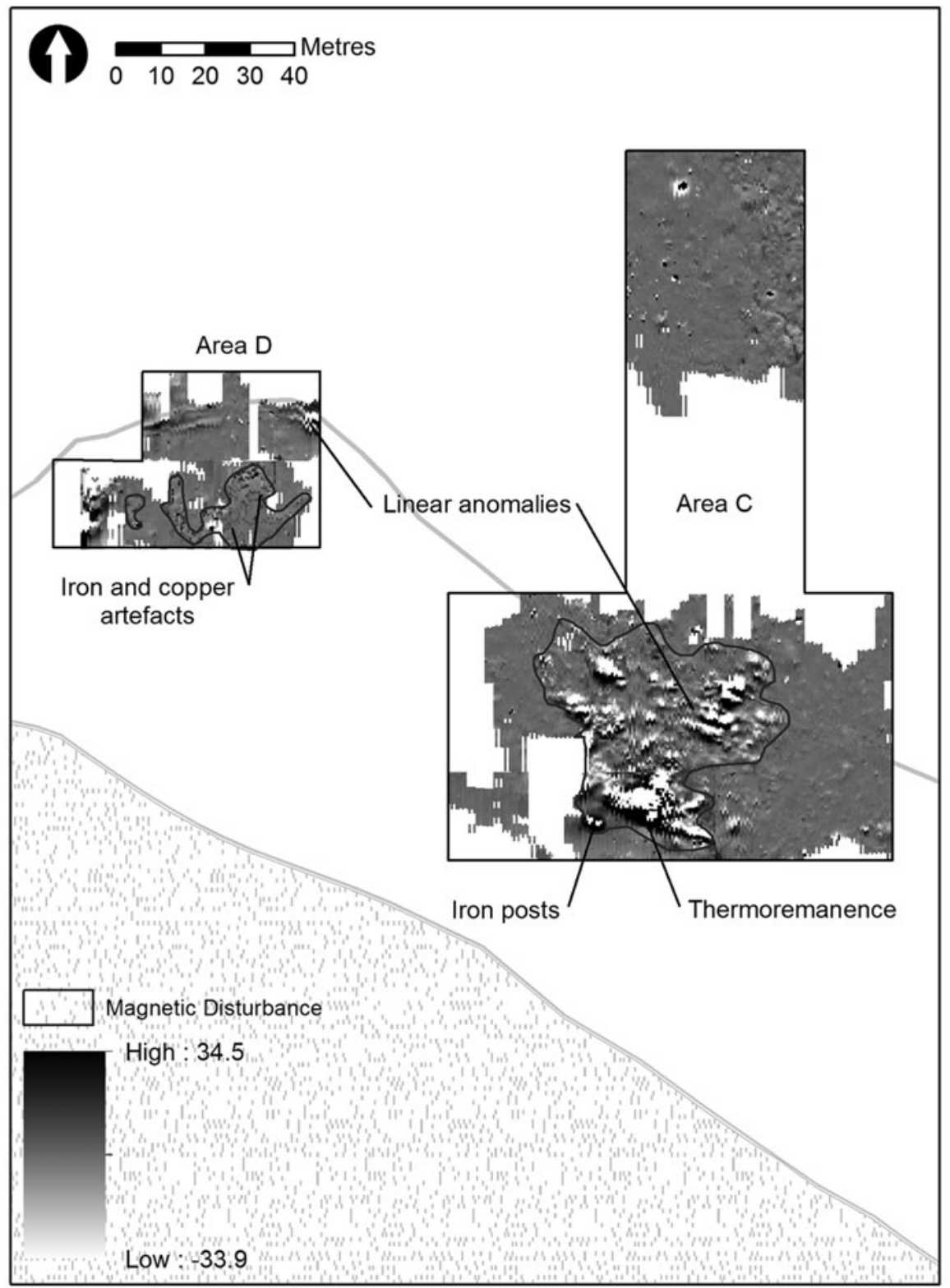

Figure 7. Magnetometry results from the survey of areas $C$ and $D$, showing the location of anomalies, iron posts, iron and copper artefacts and areas of thermoremanence.

\section{Area D}

This location to the west of area $\mathrm{C}$ was surveyed in order to give context to the find of a Swahili coin (Figure 7). Magnetic gradiometry revealed faint traces indicative of coral structures in the ploughed field where the coin was found, and two clear linear features under the roadway beyond the field. The latter features were partially visible on the (C) Antiquity Publications Ltd, 2017 
surface and identifiable as coral rubble. They are probably the remains of buried walls; the magnetometry results demonstrate a greater extent than that visible on the ground. Further surface and metal-detected finds included a fragment of a flat bronze disc, possibly a mirror, with decorative script; four coins; and a small number of other non-ferrous artefacts. No diagnostic ceramics were found at this location, but the coins suggest that this area of the site dates to the thirteenth to fifteenth centuries AD.

\section{Discussion}

The results from this pilot season of geophysical survey add significantly to our information on the site of Unguja Ukuu. The identification of dipolar anomalies in area A, around 15$20 \mathrm{~m}$ from the creek, suggests that this was a site of industrial, as well as midden, activity. The iron ore and slag recorded in this area by Horton (in press) may indicate iron-working in this zone. The fact that this is so close to the assumed position of the settlement suggests that this industry was central to the daily life of the site, even while it was related to the maritime zone. This confirms some of the ways that we understand daily life and craft activity to have been intertwined in early Swahili ports.

In area $\mathrm{B}$, we identified structural remains comprising a significant quantity of Porites coral, which formed a linear feature on an alignment of $330^{\circ}$. The materials and alignment indicate the former presence of a mosque. The fragmentation of the coral indicates the robbing of larger coral blocks from this structure, and small fragments of imported ceramics suggest that this robbing may have occurred in the thirteenth to fourteenth centuries AD. We have also identified a previously unknown timber or wattle-and-daub structure adjacent to this mosque, which appears to date to an early period in the seventh-tenth-centuries AD phase of occupation. The relationship between this timber structure and the coral phase of the mosque is presently unclear, but on the basis of the small area excavated so far, three hypotheses can be put forward:

1) The timber structure pre-dates the mosque and is part of an unrelated structure.

2) The timber structure was contemporaneous with the earliest phase of the mosque but was physically unrelated.

3) The timber structure represents the earliest phase of the mosque, which was later redeveloped as a coral building.

Charcoal samples have been obtained from various contexts in the excavation of this structure, and will be submitted for dating. Further excavation of the interior will be necessary to confirm its date and function. At this stage, however, it is worth noting that its discovery indicates the possible extension of the settlement into the area adjacent to the ocean, and perhaps a southern extension of early Unguja Ukuu from the mainland onto the peninsula. The evidence from area B therefore extends the limits of the settlement to encompass a busy waterfront including a mosque, perhaps for the use of sailors and merchants arriving at the site. Port facilities on this waterfront seem to have faced the open water of Menai Bay, rather than the shelter of the tidal creek. This alters our interpretation of the orientation of the public waterfront and, by extension, the relationship between the whole port and its surrounding maritime context. It also challenges the current theory 
that early mosques were centrally situated within urban zones in Swahili towns, and might point to multiple processes of Islamicisation in different regions of East Africa (cf. Horton 1991).

In area $\mathrm{C}$ we were able to rule out present-day debris and interference as the cause of the magnetic anomaly identified in 2013, but the recovery of several British coins from the 1930 s, and the discovery of concrete and metal posts near the shoreline, indicates that it is probably related to twentieth-century activity. It is possible, however, that these remains are unrelated and that an earlier phase of activity is still preserved in this area.

The discovery of early Swahili coinage in area $\mathrm{D}$, along with various other metal artefacts and several coral-rag walls, indicates that this was occupied around the fourteenth to fifteenth centuries AD. It seems that the settlement at Unguja Ukuu may have shifted over time, or have been redeveloped on several occasions, although the nature of these moves, along with their purpose or consequence, is as yet unclear. Further work is necessary to investigate the size of the settlement in this period, especially as the picture is complicated by recent building and earthworks on the site, which make surface observations more difficult.

Collectively, these results indicate that during the early occupation of Unguja Ukuu, between the seventh and tenth centuries $\mathrm{AD}$, the town occupied a prominent coastal location with maritime access from the sea via Menai Bay, and with exploitation of the various resources of the mangrove creek east of the peninsula. In this scenario, the newly identified mosque found in area B probably marked the limit of the harbour, as seen at other Swahili coastal towns in later periods (Fleisher et al. 2015). It may have had a counterpoint farther west along the beach in the form of another mosque. As well as demonstrating the presence of a local Islamic community at this date, the harbour-edge mosques would have served as beacons to passing or incoming maritime traffic. There is a contrast between the position of this mosque, on the edge of the settlement near the ocean, and the central mosque of similar date at Shanga, a site on the north Kenya coast that has been the type-site by which urban Islam has been understood for this region. At Shanga, a model has been suggested by which the mosque occupied a central space with access controlled by different social groups (Horton 1991). Islam was therefore at the heart of the settlement (spatially and figuratively) from the start. At Unguja Ukuu, a mosque on the edge of the site, facing the ocean, might suggest a somewhat different role, with the outward-facing aspect of the mosque being prioritised. This suggests more diversity in the route to Islamicisation than has previously been recognised.

The industrial zone in area A was probably related to the working of the harbour. Furthermore, the location of the mosque 'beyond' this area relative to the known occupation zone creates a larger site boundary that includes this harbour/industry area, positioning it within the orbit of the settlement rather than on the edge. It may be that in addition to the usual necessities of boat building and repair, and fishing and trade, industry formed a key component of harbour activity at Unguja Ukuu.

The successful identification of so many previously unknown archaeological features demonstrates the potential both for further work at Unguja Ukuu, and for geophysical survey in East Africa in general. We have been able to extend the known limits of Unguja Ukuu, re-orient the site in relation to its harbour facilities and raise questions about the relationship between public and working spaces in early Swahili society.

(C) Antiquity Publications Ltd, 2017 


\section{Understanding the layout of early coastal settlement at Unguja Ukuu, Zanzibar}

\section{Acknowledgements}

Fieldwork was conducted in collaboration with the Department of Museums and Antiquities, Zanzibar. We would like to thank Amina Issa, Director, and Abdallah Khamis Ali, Director of Antiquities, for their support. Research was funded by the Entrepôt Project of the Danish Council for Independent Research Sapere Aude programme (PI Søren Sindbæk). Fieldwork was conducted by Stephanie Wynne-Jones, Tom Fitton, Søren Sindbæk, Jason Hawkes, Sarah Croix, Mateusz Bogucki and Elizabeth Bogucki. Thanks are also due to the University of York for the loan of equipment and time in the field. Stephanie Wynne-Jones is currently funded by a Pro Futura Scientia Fellowship at the Swedish Collegium for Advanced Study, affiliated with the Department of Archaeology and Ancient History, Uppsala University. She is a core group member of the DNRF-funded Centre for Urban Network Evolutions, Aarhus University (DNRF199).

\section{References}

Boivin, N., A. Crowther, M. Prendergast \& D.Q. Fuller. 2014. Indian Ocean food globalisation and Africa. African Archaeological Review 31: 547-81. https://doi.org/10.1007/s10437-014-9173-4

Chami, F. 2001. Chicken bones from a Neolithic limestone cave in Zanzibar, in F. Chami, G. Pwiti \& C. Radimilahy (ed.) People, contacts and the environment in the African past: 81-97. Dar es Salaam: University of Dar es Salaam Press.

- 2009. Zanzibar and the Swahili coast from c. 30,000 years ago. Dar es Salaam: E \& D.

Fleisher, J.B. 2003. Viewing stone towns from the countryside: an archaeological approach to Swahili regional systems, AD 800-1500. Unpublished PhD dissertation, University of Virginia.

- 2010. Swahili synoecism: rural settlements and town formation on the central East African coast, A.D. 750-1500. Journal of Field Archaeology 35: 265-82. https://doi.org/10.1179/009346910X12707321358919

Fleisher, J.B. \& A. LaViolette. 2013. The early Swahili trade village of Tumbe, Pemba Island, Tanzania, AD 600-950. Antiquity 87: 1151-68. https://doi.org/10.1017/S0003598X00049929

Fleisher, J.B. \& S. Wynne-Jones. 2011. Ceramics and the early Swahili: deconstructing the Early Tana Tradition. African Archaeological Review 28: 245-78. https://doi.org/10.1007/s10437-011-9104-6

Fleisher, J.B., S. Wynne-Jones, C. Steele \& K. Welham. 2012. Geophysical survey at Kilwa Kisiwani, Tanzania. Journal of African Archaeology 10: 207-20. https://doi.org/10.3213/2191-5784-10220

Fleisher, J.B., P. Lane, A. LaViolette, M.C. Horton, E. Pollard, E. Quintana Morales, T. Vernet, A. Christie \& S. Wynne-Jones. 2015. When did the Swahili become maritime? American Anthropologist 117: 100-15. https://doi.org/10.1111/aman.12171
Horton, M.C. 1991. Primitive Islam and architecture in East Africa. Muqarnas: an Annual on Islamic Art and Architecture 8: 103-16.

- In press. Zanzibar and Pemba. Nairobi \& London: British Institute in Eastern Africa.

Horton, M.C. \& C.M. Clark. 1985. Zanzibar archaeological survey. Azania 20: 161-71. https://doi.org/10.1080/00672708509511362

Juma, A. 1996. The Swahili and the Mediterranean worlds: pottery of the Late Roman period from Zanzibar. Antiquity 70: 148-54. https://doi.org/10.1017/S0003598X00083009

- 2004. Unguja Ukuu on Zanzibar: an archaeological study of early urbanism. Uppsala: Societas Archaeologica Upsaliensis.

LaViolette, A. \& J.B. Fleisher. 1995. Reconnaissance of sites bearing Triangular Incised (Tana Tradition) Ware on Pemba Island, Tanzania. Nyame Akuma 44: 59-65.

Sinclair, P., A. Juma \& F. Chami. 2006. Excavations at Kuumbi Cave on Zanzibar in 2005, in F. Chami (ed.) Studies in the African past: 95-106. Dar es Salaam: University of Dar es Salaam Press.

Walshaw, S.C. 2010. Converting to rice: urbanization, Islamization and crops on Pemba Island, Tanzania, AD 700-1500. World Archaeology 42: 137-54. https://doi.org/10.1080/00438240903430399

- 2015. Swahili urbanisation, trade and food production: botanical perspectives from Pemba Island, Tanzania AD 600-1500 (British Archaeological Reports international series S2755). Oxford: Archaeopress.

Welham, K., J. Fleisher, P. Cheetham, H. Manley, C. Steele \& S. Wynne-Jones. 2014. Geophysical survey in sub-Saharan Africa: magnetic and electromagnetic investigation of the UNESCO World Heritage Site of Songo Mnara, Tanzania. Archaeological Prospection 21: 255-62. https://doi.org/10.1002/arp.1487 
WyNNE-JONES, S. 2012. Exploring the use of geophysical survey on the Swahili coast: Vumba Kuu, Kenya. Azania 47: 137-52.

https://doi.org/10.1080/0067270X.2012.677324
Wynne-Jones, S. \& J.B. Fleisher. 2012. Coins in context: local economy, value and practice on the East African Swahili coast. Cambridge Archaeological Journal 22: 19-36.

https://doi.org/10.1017/S0959774312000029

Received: 15 January 2016; Accepted: 26 August 2016; Revised: 1 February 2017

(C) Antiquity Publications Ltd, 2017 